\title{
Admiral Nursing: combining specialist dementia and hospice care
}

\author{
Karen Harrison Dening ${ }^{1 *}$, Jacqueline Crowther ${ }^{2}$ and Sharron Tolman ${ }^{3}$ \\ ${ }^{1}$ Dementia UK, 356 Holloway Road, London, N7 6PA, UK \\ ${ }^{2}$ Kirkwood Hospice, Dalton Green Road, Dalton HD5 9UY, UK \\ ${ }^{3}$ St Cuthbert's Hospice, Park House Road, Durham, DH13QF, UK
}

\begin{abstract}
More people are living longer and as such influence both the prevalence and incidence of age-related conditions such as dementia with one in three people now dying with or from the condition. However, dementia has not traditionally been seen as 'terminal' or 'life limiting' syndromes and enjoyed equal access to palliative and end-of-life care services such as hospice care. This is changing. This paper presents two case studies where Admiral Nurses (specialists in dementia care) have been commissioned by hospices to develop their scope and practice to include families affected by dementia.
\end{abstract}

\section{Introduction}

\section{Ageing and dementia}

More people are living longer in old age [1]. In the UK alone, the percentage of older people (aged 65 years and over) has grown by $47 \%$ since 1974 increased to make up nearly $18 \%$ of the total population in 2014 [2]. The numbers of those reaching the oldest ages are increasing the fastest: in 2008, there were 1.3 million people in the UK aged 85 and over, with this expected to increase to 1.8 million by 2018 and to 3.3 million by 2033 [3]. These changes to the age structure of the population influence both the prevalence and incidence of age-related conditions such as dementia [4].

\section{What is dementia?}

Dementia is a term used to describe a syndrome; a collection of symptoms, including a decline in memory, reasoning and communication skills, and a gradual loss of skills needed to carry out daily living activities. These symptoms are caused by structural and chemical changes within the brain as a result of neurodegenerative changes. The cognitive changes arising in dementia are determined to a large extent by the areas of the brain that are affected by the underlying pathological processes. These processes include tissue destruction, compression, inflammation, and biochemical imbalances. In other words, the process of dementia is the end stage manifestation of numerous brain disorders [5-7].

\section{Dementia: A life limiting condition}

As life expectancy increases so people often develop a range of conditions and disabilities in the years before death [8]. Frail older people (including those with dementia) are the greatest users of health and social care [9]. Despite this, dementia and frailty have not traditionally been seen as 'terminal' or 'life limiting' syndromes [10]. In one study surveying carers and physicians, at nursing home admission, they perceived only $1.1 \%$ of residents to have life expectancy of less than 6 months. However, $71 \%$ of those residents died within that period of time [11]. Acute physical illness, such as pneumonia or urinary tract infection, may be an indicator of imminent death in people with advanced dementia [12-14]. Dementia is a progressive, irreversible neurodegenerative condition, [15], and once diagnosed people will die with dementia regardless of the primary cause of death [16]. Xie et al. [15], in analysis of a longitudinal population based cohort study, reported a median survival time from symptom onset of dementia to death was 4.5 years concluding one in three people (30\%) will die with or from dementia. Although dementia has been identified as the leading causes of death in England [17], exact numbers of deaths where dementia is a primary or secondary cause may still remain uncertain due to under-reporting on death certificates [18]. Despite this there is still widespread evidence people with dementia have inequitable access to good palliative and end of life care.

\section{Palliative and end of life care in dementia}

Palliative care is an approach that improves the quality of life of patients and their families facing the problems associated with life threatening illness, through the prevention and relief of suffering by means of early identification and impeccable assessment and treatment of pain and other problems, physical, psychosocial and spiritual [19]. Palliative care, as a term, is still often only associated with cancer, whereas end-of-life care refers to all patients with life limiting illnesses. However, in European countries end-of-life care is often used to describe the care given during the last few hours or days of life.

The European Association of Palliative Care (EAPC) published a consensus statement attempting to define the principles of palliative care for people with dementia [20]. All definitions of palliative care

Correspondence to: Karen Harrison Dening, RMN, RNLD, RN, MA, PhD, Head of Research and Publications, Dementia UK, 356 Holloway Road, London, N7 6PA, UK, E-mail: Karen.Harrison-Dening@dementiauk.org

Key words: dementia, palliative care, end-of-life care, innovative practice

Received: April 09, 2017; Accepted: May 01, 2017; Published: May 04, 2017 
share a common philosophy of care which is to take a holistic approach, valuing autonomy of the patient and their family, with a focus on comfort and dignity, a collaborative relationship between health care professionals with patients and their families, good communication, and a central goal to maintain quality of life for the person until death. It is also important to note that end of life care "seeks neither to hasten death, nor to postpone it" [21].

\section{Hospice and dementia}

Dementia care is an increasingly important strategic consideration for hospices in the UK. In 2014 Hospice UK (www.hospiceuk.org/) embarked upon a yearlong project with a UK dementia charity, Hope for Home. One of the main aims of Hope for Home is to support people with dementia to live well in the community until they die. A large element of their work is focused on supporting people with dementia to die at home in familiar surroundings with familiar people around them. The project was managed by the Practice Development Lead from Hospice UK. It was informed from a dementia perspective by an individual with dementia experience and expertise and a steering group of nationally recognised experts in the field of dementia care and palliative and end of life care.

The project explored the current position of dementia care provision in UK hospices and their position and thinking in relation to them extending their reach and including those living and dying with dementia and their carers, in their everyday practice and service development. The findings were interesting and revealed a number of UK hospices were already embracing dementia in creative ways. However, it also revealed a number of UK hospices felt that dementia was not within their remit, did not consider it to be a life limiting illness and had no plans or intentions to include dementia in future service development or strategic planning. Whilst this was a concern, it was also acknowledged a number of UK hospices reflected they may not have the most suitable physical environments to support people with dementia and their carers and needed to consider their contribution to dementia care in more creative ways.

During the project, the question of how can hospices be best supported to include dementia in their everyday practice began to emerge. As a result, and in an attempt to answer this question, specific guidance for hospice was written and published [22]. The guidance is aimed to steer hospice from the very first steps of auditing and reviewing their current position, to implementing creative dementia friendly services. How to do this within existing resources and how to explore new ones is covered in this guidance along with how to manage sustainability. This guidance is now a very familiar sight in UK hospices. A number of hospices have used this guidance to support their strategic planning and the development and implementation of dementia specific services. There are a growing number of hospice that are employing Admiral Nurses to progress their strategy.

\section{Admiral Nursing}

Admiral Nursing was established as a result of the experiences of family carers to uniquely join the different parts of the health and social care system and enable the needs of family carers and people with dementia to be addressed in a coordinated way [23] (Table 1).

Many people newly diagnosed with dementia find health and social care bewildering, and find the system difficult to navigate. The Admiral Nursing model was developed to provide case management [24] for families affected by dementia to be better able to cope, enable people with dementia to stay at home, and to live more independently and positively with their condition. Admiral Nurses work across a variety of NHS organisations (primary, secondary, acute and community care) as well as in social care, care home and hospice settings. Central to their role is case management using the Admiral Nurse Assessment Framework (an 18 domain assessment schedule of the needs of both the person with dementia and the family carer) to underpin their care of families affected by dementia.

This paper will now consider two cases where Dementia UK has worked in partnership with two hospices to implement the Admiral Nursing model to enhance their approach in support of families affected by dementia.

\section{Case study 1: Sharron Tolman, Admiral Nurse at St Cuthbert's hospice, County Durham}

St Cuthbert's hospice [25] was the first hospice in the UK to appoint an Admiral Nurse in 2014. The hospice strategy and vision at that time identified the need to develop services to support people with dementia and their families and felt an Admiral Nurse would be the best place to start. When the Admiral Nurse, Sharron Tolman, first joined the hospice 2014, it initially felt daunting; quite literally Sharron felt she was starting with a blank piece of paper. However, Sharron quickly learnt that the ethos of good hospice care chimed with the principles of good dementia care; seeing the person before the illness [26] and involving and supporting all those around the person who may also be affected by the illness. Whilst hospice staff are very skilled

Table 1. The Admiral Nurses service approach.

\section{The Admiral Nurses service approach}

Admiral Nurses focus on the needs of the whole family affected by dementia, including psychological support to help the person with dementia and family carers to understand and deal with their thoughts, feelings and behaviour, and to adapt to the changing situation. Care giving involves a change in on going patterns of exchange between the caregiver and care recipient. Both the care giver and recipient have to adjust to the transformation of their relationship into a care giving relationship; this includes a change in the balance of roles, as the care giver takes more responsibility for the welfare of the recipient. Admiral Nurses can offer expert input here.

Admiral Nurses use arrange of specialist interventions that help people live well with the condition and develop skills to improve communication and maintain relationships. The current government-led dementia strategy emphasizes early diagnosis, early interventions and support, inter-sectorial support and integrated working and support for carers.

Admiral Nurses work with families is an invaluable source of contact and support at particular points of difficulty in the dementia journey, including diagnosis, when the condition progresses, or when tough decisions need to be made, such as moving a family member into residential care. Anticipated problems are misdiagnosis, delayed diagnosis, and lack of information and services for people with dementia and their families, which give rise to the risk for inappropriate management, crises, poor psychological adjustment to the diagnosis, reduced coping capacity and ability to forward plan.

Admiral Nurses help families cope with feelings of loss and bereavement as the condition progresses. There is an acknowledgement that family care does not end once "hands-on" care giving ceases. Dementia guideline support the principle that family carers should be supported during the illness of dementia and into bereavement. For family carers, the more social support that is received during the years of care giving, the easier it is to adjust and adapt post bereavement.

Admiral Nurses provide advice on referrals to the appropriate services and liaise with other health professionals on behalf of the family. Such knowledge may help them provide general information, as opposed to just that which is medical (such as further diagnosis and management of medical problems). For example, a nursing specialist could potentially make timely referrals, if needed, to sources of specialist legal advice and use current leg islation to reduced is putes [23]. 
in dealing with complex issues and patient/family distress, dementia still carries fear and stigma and a worry about what to do and hospice staff feeling they lack the confidence and skills to care. This can result in a reduced understanding of a person's needs. So, some of the Sharron's role has been in building staff's confidence and interest in caring for people with dementia. Teaching is important but changing culture and getting people to think differently and feel passionate about dementia care is required to embed best dementia care and practice with more sustainability. Sharron would often think 'what difference have I made? Are people doing things differently?' Reflection of this sort helps Sharron to see how she can improve and develop services using her expert knowledge and skills in dementia care. She began by encouraging staff and volunteers from all hospice departments to learn a little more about dementia. People began to talk about it and Sharron remembers a housekeeper saying to her 'isn't' dementia so interesting!' (Figure 1).

Sharron also began to have a voice in multidisciplinary meetings with the terminology used is beginning to change to embrace a more person centred ethos; for example, 'distress behaviours' are talked about now rather than 'challenging behaviours'. Sharron acts as a source of support, consultation and resource for various issues, such as, deprivation of liberty legislation (DOLs), capacity and cognitive assessments [27]. She has also introduced and embedded assessment tools for specific tools to assess delirium and pain in dementia $[28,29]$. Any difficulties faced, Sharron encourages reflective practice and for staff to seek solutions for improvement the next time, and also in considering changes to the environment for example. Sharron recognises that it is not a quick fix and hospice environments are not necessarily ideal or appropriate care settings for everyone with dementia but have developed strong partnerships with other local services and work collaboratively to seek solutions.

Still few people with dementia die in hospices so a large part of Sharron's work is community based, working with family carers to build their confidence, knowledge and skills. She mostly works with people with advanced dementia, perhaps in the last year or two of life but is frequently contacted by families looking after people at all stages of the dementia trajectory. Her engagement with the wider community brings new people to the attention of the hospice all the time which has also contributed to the shaping of services. St Cuthbert's now hosts a cognitive stimulation group in its well-being centre aimed at people

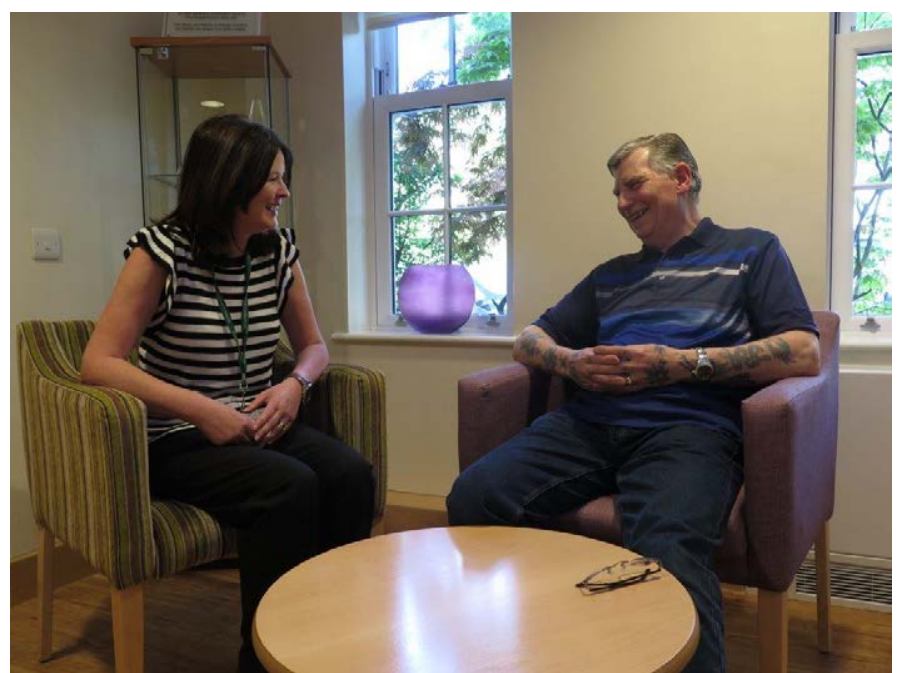

Figure 1. Case study one image - Sharron Tolman, St Cuthbert's Admiral Nurse. with mild to moderate dementia and also a Namaste Care [30] at home service for people with advanced dementia. Sharron trains volunteers to visit people at home and provide sensory based stimulation and interaction for people with dementia, showing family carers new or different ways of remaining connected with the person with dementia. Carers of people with dementia can now also access complimentary therapies that are offered routinely to other family carers by the hospice. Sharron's role is to both plan and initiate these services and ensure the staff have the confidence and ability to take them forward, offering support where needed.

Sharron feels the scope of possibilities to be endless and that it is a pleasure to work alongside these people highly skilled in palliative and end-of-life care and to have had the opportunity to grow the dementia service with them. She reflects that the palliative care approach reminds us all that dementia is a 'disease' of the brain and much of her work is in helping the wider health and social care community see dementia through a palliative lens which gains a completely different perspective, one, Sharron feels, that brings one that is fresh, hopeful and thoughtful.

\section{Case study 2 - Jacqueline Crowther, end of life care Admiral Nurse at Kirkwood hospice, Huddersfield}

Kirkwood Hospice [31] in Kirklees West Yorkshire, along with a number of other geographical areas in the UK, has an increasing ageing population. It is worthy of note that Kirklees also has growing numbers of people from black and minority ethnic groups (BAME), notably of Afro-Caribbean communities who are also ageing. In Kirklees it is estimated there are 4,800 people currently living with a diagnosis of dementia, approximately 600 of these are at the advanced, tertiary point in the disease trajectory.

Kirkwood Hospice is one of those hospices who acknowledged some time ago their role and responsibility in relation to dementia care. Dementia is included in their strategic plan and the Director of Clinical Services has also written a Dementia Strategy for Kirkwood Hospice. Unlike some other UK hospices, they have historically considered and cared for people with dementia and their carers across the range of services they offer, including in-patient care. However, also similar to other UK hospices, admission for in-patient care has a tendency to be as a result of another life limiting illness, i.e. cancer and not related to a primary diagnosis of dementia or a diagnosis of dementia alone. There is also an acknowledgement development of staff and the provision of more services is necessary in order to support people with dementia and their carers more effectively (Figure 2).

In Kirklees there is commitment from health and social care providers in relation to dementia care. Both have developed Dementia Strategies and Needs Assessments in relation to dementia care. Coincidentally, Kirklees also has one of the largest Admiral Nursing teams nationally, employed by the Mental Health Trust. The Kirkwood Hospice End of Life Care Admiral Nurse, Jacqueline Crowther, is a new initiative and she has been in post six months. The post has received funding from the hospice and different local organisations. It supports all elements of the hospice strategic plan; developing and making best use of resources and staff, extending Kirkwood Hospice's reach and delivering high quality end of life care to all those who need it. This post sits within the Specialist Community Palliative Care Team based at Kirkwood Hospice and an open referral system is in place.

Jacqueline's role is multi-faceted and includes; individual casework and carer support, training and development of hospice staff (including volunteers) and those from other organisations, consultancy and 


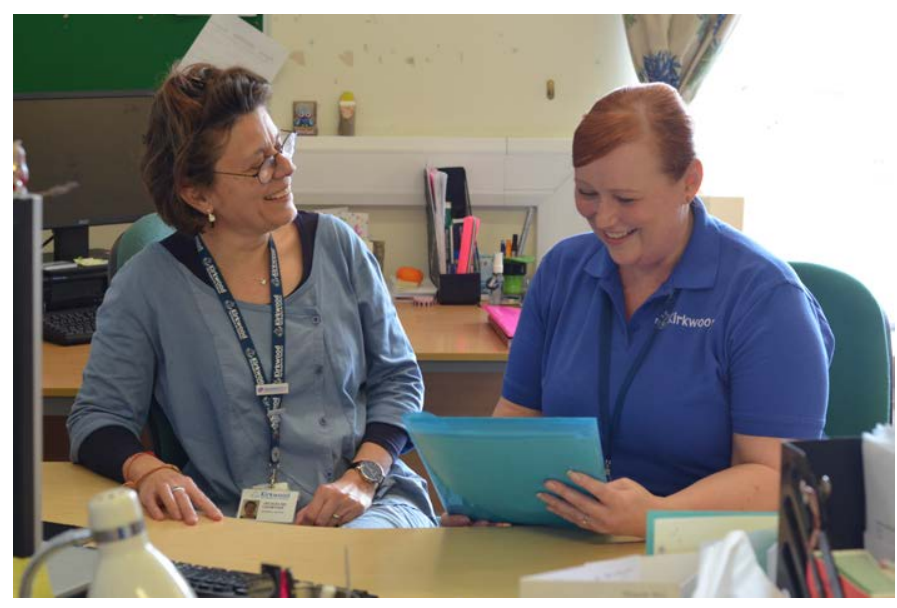

Figure 2. Case study two image - Jacqueline Crowther, Kirkwood Hospice Admiral Nurse.

advisory work, linking with local strategic clinical networks, supporting development of local strategies and policies, individual advance care planning, advising on and supporting the development of dementia services across the hospice, promoting best practice in end of life care for people with dementia and embedding this within Kirkwood Hospice and wider organisations in time. Another important aspect of her role is to promote the work of Kirkwood Hospice in relation to dementia care amongst the local community. As a large part of Jacqueline's role is focused on staff development and consultancy she envisages she will also hold a small caseload of people with dementia and their carers where their needs are complex and require a case management approach [24].

Jacqueline argues one of the benefits of having a number of other services locally supporting people with dementia and their carers at different points in the disease trajectory, is the hospice Admiral Nurse is more able to focus on advance care planning at an earlier point but also ensure if the opportunity is missed at an earlier stage, then people with dementia and their carers are supported to access the most appropriate end of life care required and available at that time. Jacqueline feels in a privileged position, being able to support people and families affected by dementia to have, what can be for some, a difficult conversation about future planning and to support people as end of life approaches.

As with the St Cuthbert's Admiral Nurse, development of hospice staff and those from a number of other organisations in relation to delivery of good end of life care for people with dementia is a key element of the role. However, in Kirklees this also includes the existing local Admiral Nursing team so Jacqueline supports them with the development of their knowledge and skills in relation to end of life care for people with dementia. She will achieve this through the delivery of master classes in end of life care for people with dementia, joint assessment and working and role modelling.

In the short time Jacqueline has been in post she has undertaken the following activities; contributed to and initiated mental capacity assessments and best interest meetings pertaining to end of life, both within and outside the hospice, reviewed hospice documentation and recording of dementia, acted in an advisory and consultancy capacity with hospice colleagues, GPs, learning disability organisations, Health and Social Care colleagues and reviewed the hospice's physical environment and advised on its suitability and necessary adaptations to facilitate people with dementia and their carers.

\section{Benefits of a collaborative approach between dementia}

\section{and hospice care}

Professionals working in the field of dementia care and palliative and end-of-life care have long been aware of a growing need to ensure people with dementia and their family carers receive the best possible care as end of life approaches for the person with dementia. Dementia UK established a special interest group for palliative and end of life care in 2008 to scope the practice development needs of Admiral Nurses to be better able, in knowledge and skills, to meet the needs of families affected by dementia at the end-of-life [32]. What became apparent during this project was that knowledge and skills in this area often spanned the specialities of dementia and palliative care and whilst joint working could be facilitated in complex cases, there needed to be focused approach to bring together both specialities.

Dementia UK has now developed over six partnerships with hospices across the UK where hospices have employed an Admiral Nurse with the wider interest growing. St Cuthbert's and Kirklee's are two examples of how the Admiral Nursing model can be of utility within the hospice setting. Early evaluations are highlighting many benefits to this close collaboration with the Kirklee's partnership undergoing a rigorous service evaluation and impact study due for completion and reporting early 2018.

Apart from this development of local partnerships Dementia UK and Hospice UK held an event, inviting professionals from both dementia care and palliative and end-of-life care, to establish a community of practice $(\mathrm{CoP})$ that has as its focus the sharing of practice, knowledge and expertise in their respective fields to support shared learning. At the inaugural meeting delegates participated in a nominal group technique (NGT) to collectively identify their learning needs from the CoP [33]. Through the use of the NGT, 15 learning needs were identified with five being ranked highest by the participants in terms of their perceived need for developing their knowledge and skills in palliative and end-of-life care in dementia [33]:

$>$ Developing skills to enable better communication as they care for the person with dementia

$>$ Meeting the educational needs of the wider team regarding dementia care

$>$ Understanding and influencing policy and strategy for palliative and end-of-life care in dementia

\section{$>$ Understanding issues for dementia care in different settings \\ $>\quad$ Pain assessment and management in dementia}

Participants' equally, across dementia care, palliative and end-oflife care and those that work specifically with both, all expressed the need for further knowledge and skills in effective communication with people with dementia at the end of life. However, palliative and end-of-life care specialists felt they needed to understand how to better communicate with people with advanced dementia where communication presented a barrier and dementia care specialists wanted to understand how better to have difficult communication and conversations about end-of-life care symptoms. It became evident that each group of specialists held the knowledge and skills that each other desired. Thus the $\mathrm{CoP}$ is in its second year with a growing membership and spread across the UK $[34,35]$.

\section{Summary/key practice points}

There is a growing interest in the exploration and application of 
traditional models of palliative and end of life care to dementia. Hospice is historically known for excellent care of people dying with cancer. As with cancer, dementia is a complex, life limiting condition and incidence increases with age. Both conditions require skilled care by professionals who understand the significant impact on physical, emotional, spiritual and social well-being for whole families. The merging of two specialists, as with Admiral Nursing and Hospice is an innovative response to the national and international calls for partnerships across organisations to share knowledge and expertise and embrace dementia as a life limiting illness. In doing so it provides high quality and expert care to families affected by dementia and addresses some of the inequalities in end of life care by facilitating equitable access to good palliative and end of life care in a timely manner to all those in need.

\section{References}

1. ONS (2016a) UK Perspectives 2016: The changing UK population. http://www.visual. ons.gov.uk/uk-perspectives-2016-the-changing-uk-population[Accessed 6 February 2017].

2. ONS (2013) Population Estimates for UK, England and Wales, Scotland and Northern Ireland. http://www.ons.gov.uk/ons/rel/pop-estimate/population-estimates-for-uk--englandand-wales--scotland-and-northern-ireland/2009/index.html[Accessed 6 February 2017].

3. Stephan B, Brayne C (2008) Prevalence and projections of dementia. In: Downs M, Bowers S (editors) Excellence in Dementia Care: Research into practice, Maidenhead: McGraw-Hill,

4. Wilcock G, Bucks R, Rockwood K (1999) Diagnosis and Management of Dementia: A Manual for Memory Disorders Teams, Oxford: Oxford University Press.

5. Fratiglioni L, Qiu C (2013) Chapter 31: Epidemiology of dementia. In: Dening T, Thomas A (editors) 2nd edition, Oxford Textbook of Old Age Psychiatry, Oxford: Oxford University Press.

6. Nuffield Council on Bioethics (2009) Dementia: ethical issues, London: Nuffield Council on Bioethics.

7. Luengo-Fernandez R, Leal J, Gray A (2010) Dementia 2010. London: Alzheimer's Research Trust.

8. Matthews FE, Arthur A, Barnes LE, Bond J, Jagger C, et al. (2013) A two-decade comparison of prevalence of dementia in individuals aged 65 years and older from three geographical areas of England: results of the Cognitive Function and Ageing Study I and II. Lancet 382 (9902): 1405-1412.

9. Kulmala J, Nykänen I, Mänty M, Hartikainen S (2014) Association between frailty and dementia: a population-based study. Gerontology 60: 16-21.[crossref]

10. Sampson EL, Harrison Dening K (2013) Palliative care and end of life care. In: Oxford Textbook of Old Age psychiatry, $2^{\text {nd }}$ edition, Dening T, Thomas A (editors) Oxford: Oxford University Press.

11. Mitchell SL, Kiely DK, Hamel MB (2004) Dying with advanced dementia in the nursing home. Arch Intern Med 164: 321-326.[crossref]

12. Mitchell SL, Teno JM, Kiely DK, Shaffer ML, Jones RN, et al. (2009) The clinical course of advanced dementia. $N$ Engl J Med 361: 1529-1538.[crossref]

13. Morrison RS, Siu AL (2000) Survival in end stage dementia following acute illness. JAMA284 (1): 47-52.[crossref]

14. Sampson EL, Blanchard MR, Jones L, Tookman A, King M (2009) Dementia in the acute hospital: prospective cohort study of prevalence and mortality. $\mathrm{Br} J$ Psychiatry 195: 61-66.[crossref]

15. Xie J, Brayne C, Matthews FE; Medical Research Council Cognitive Function and Ageing Study collaborators (2008) Survival times in people with dementia: analysis from population based cohort study with 14 year follow-up. BMJ 336: 258-262. [crossref]

16. Wilcock J, Froggatt K, Goodman C (2008) End of Life Care. In: Downs M, Bowers $\mathrm{S}$ (editors) Excellence in Dementia Care: Research into Practice, Maidenhead: Open University Press.

17. ONS (2016b) Death registered in England and Wales (Series DR): 2015. http://www. ons/gov.uk/peoplepopulationandcommunity/birthsdeathsmarriages/deaths/bulletins/de athregisteredinengland[Accessed 6 February 2017].

18. Martyn CN, Pippard EC (1988) Usefulness of mortality data in determining the geography and time trends of dementia. J Epidemiol Community Health 42: 134-137. [crossref]

19. Gómez-Batiste X1, Porta-Sales J, Pascual A, Nabal M, Espinosa J, et al. (2007) Catalonia WHO palliative care demonstration project at 15 Years (2005). J Pain Symptom Manage 33: 584-590.[crossref]

20. Van der Steen JT, Radbruch L, Hertogh CMPM, de Boer ME, Hughes J, et al. (2014) White paper defining optimal palliative care in older people with dementia: A Delphi study and recommendations form the European Association for palliative Care. Palliat $\operatorname{Med28(3):~197-209.[crossref]~}$

21. Payne S, Radbruch L 92009) White Paper on standards and norms for hospice and palliative care in Europe: part 1 Recommendations from the European Association for Palliative Care. European Journal of Palliative Care 16(6): 278-289.

22. Hospice UK (2015) Hospice enabled dementia care: The first steps, a gudie to help hospices establish care for people with dementia and their families. Hospice UK. London.

23. Rahman S, Dening KH (2016) The need for specialist nurses in dementia care. Nurs Times 112: 14-17. [crossref]

24. Dening KH, Aldridge Z, Pepper A, Hodgkison C (2017) Admiral Nursing: case management for families affected by dementia. Nurs Stand 31: 42-50.[crossref]

25. www.stcuthbertshospice.com/215/2/St-Cuthberts-Hospice-Dementia-Support

26. Kitwood T (1997) Dementia Reconsidered: The person comes first, Buckingham: Open University Press.

27. HMSO (2005) Mental Capacity Act 2005. http://www.legislation.gov.uk/ukpga/2005/9/ contents[Accessed 6 February 2017]

28. Schuurmans MJ, Shortridge-Baggett LM, Duursma SA (2003) The Delirium Observation Screening Scale: a screening instrument for delirium. Res Theory Nurs Pract17(1): 31-50.[crossref]

29. Abbey J, Pillr N, De Bellis A, Esterman A, Parker L, et al. (2004) The Abbey pain scale: a 1-minute numerical indicator for people with end-stage dementia. Int J Palliat Nurs 10(1): 6-13.[crossref]

30. Simard J (2013) The End-of-Life Namaste Care Program for People with Dementia Baltimore, maryland: Health Professiona Press.

31. www.kirkwoodhospice.co.uk/how-we-can-help/caring-for-patients/admiral-nurse

32. Harrison Dening K, Wharrad J (2010) Admiral Nursing: Responding to the Call for Better End of Life Care for People with Dementia. Signpost Journal of Dementia and Mental Health Care of Older People 14(3): 27-31.

33. Harrison Dening K, Cooper M (2016) Dementia Special Interest Group: Shared learning across dementia, palliative and end-of-life care domains. EoL Journal 6:1e000018.

34. Foley KM, Carver AC (2001) Palliative care in neurology. Neurol Clin 19: 789-799. [crossref]

35. www.hospiceuk.org/what-we-offer/clinical-and-care-support/hospice-enableddementia-care/dementia-end-of-life-care-community-of-practice

Copyright: (C2017 Harrison Dening K . This is an open-access article distributed under the terms of the Creative Commons Attribution License, which permits unrestricted use, distribution, and reproduction in any medium, provided the original author and source are credited. 